\title{
3D SURVEY IN COMPLEX ARCHAEOLOGICAL ENVIRONMENTS: AN APPROACH BY TERRESTRIAL LASER SCANNING
}

\author{
D. Ebolese ${ }^{1}$, G. Dardanelli ${ }^{1}$, M. Lo Brutto ${ }^{1, *}$, R. Sciortino ${ }^{1}$ \\ ${ }^{1}$ Dept. of Civil, Environmental, Aerospace, Materials Engineering (DICAM), University of Palermo, Italy \\ (donatella.ebolese, gino.dardanelli, mauro.lobrutto, rosanna.sciortino)@unipa.it
}

Commission II, WG II/8

KEY WORDS: Terrestrial Laser Scanner, 3D documentation, 3D Model, Archaeological excavation

\begin{abstract}
:
The survey of archaeological sites by appropriate geomatics technologies is an important research topic. In particular, the 3D survey by terrestrial laser scanning has become a common practice for 3D archaeological data collection. Even if terrestrial laser scanning survey is quite well established, due to the complexity of the most archaeological contexts, many issues can arise and make the survey more difficult.

The aim of this work is to describe the methodology chosen for a terrestrial laser scanning survey in a complex archaeological environment according to the issues related to the particular structure of the site. The developed approach was used for the terrestrial laser scanning survey and documentation of a part of the archaeological site of Elaiussa Sebaste in Turkey. The proposed technical solutions have allowed providing an accurate and detailed 3D dataset of the study area. In addition, further products useful for archaeological analysis were also obtained from the 3D dataset of the study area.
\end{abstract}

\section{INTRODUCTION}

Nowadays the use of different and appropriate geomatics technologies for Cultural Heritage has an important role to document and to better understand the archaeology (Galeazzi, 2016). Geomatics techniques have already proved their impact and the potential on the excavation and the post-excavation phase, increasing the quality of the archaeological documentation and enhancing the understanding of the archaeological sites (Remondino \& Campana, 2014).

Due to the complexity of the most archaeological contexts, an effective integration of different techniques is often needed for a complete 3D documentation. Actually, terrestrial laser scanning (TLS), close-range photogrammetry (CRP) and Remotely Piloted Aircraft System (RPAS) are increasingly used for specific archaeological investigations and to collect accurate and detailed 3D data. They are often integrated according to onsite requirements and to define the optimal approach to record, to classify and to manage archaeological stratigraphic data (Torres-Martinez et al., 2016).

Among the aforementioned geomatics techniques, the employment of TLS has become a common practice in the digital documentation of archaeological sites and an important approach for 3D archaeological data collection. Even though it is difficult to define a standard procedure, TLS is, indeed, a current tool for high-resolution 3D documentation of archaeological excavations. It can integrate and speed up traditional and manual survey; it can help to overcome some logistical limitations and it can provide a richer documentation describing all metric aspects of a site.

The TLS collects an accurate and detailed amount of metric data and a large quantity of 3D information, in a short time and for an immediate analysis of the archaeological evidence. In extreme environmental and lighting conditions, TLS approach would be more appropriate than others for the quality and the accuracy of 3D models (Galeazzi, 2016). Moreover, 3D models by laser scanner are useful tools for archaeologists to digitize and to extrapolate $2 \mathrm{D} / 3 \mathrm{D}$ valuable information, as plans, cross- sections, high-resolution orthophotos and accurate digital terrain models (DSM) (Lerma et al., 2010; Costantino et al., 2016). In many situations, TLS survey of the archaeological site could be very difficult due to the terrain morphology, the presence of complex archaeological structures, the environmental conditions. In this situation, a planning methodology for optimal TLS data acquisition could be a useful tool that can overcome the problems of laser scanner survey and ensure data reliability (Gonzalez-Aguilera et al., 2017). Moreover, the integration with a RPASs survey should be the best approach to acquire complete and very detailed 3D dataset (Grussenmeyer et al., 2012; Hatzopoulos et al., 2017; Lo Brutto et al., 2017).

The aim of this work is to describe the methodology chosen for a TLS survey in a complex archaeological environment according to the issues related to the particular structure of the site. The developed approach was used for the TLS survey and documentation of a part of the archaeological site of Elaiussa Sebaste in Turkey. The proposed technical solutions have allowed providing an accurate and detailed 3D dataset in short time.

\section{ELAIUSSA SEBASTE ARCHAEOLOGICAL SITE}

Elaiussa Sebaste archaeological site is close to Kizkalesi, a city located $50 \mathrm{~km}$ far from Mersin (Figure 1).

This site is of Hellenistic foundation and in the past was on an important commercial way between Cyprus and the Middle East regions.

During the reign of Augustus, Elaiussa acquired the title of Sebaste and assumed considerable importance, prospering until the beginning of the III century (Equini Schneider, 2008a). Elaiussa Sebaste then experienced, between the V and VII centuries, a renewed prosperity, witnessed by the construction of new buildings and the transformation of pre-existing monumental complexes.

The city, which originally occupied part of the peninsula, was studied and excavated by the Department of Historical, Archaeological and Anthropological Science of Sapienza 


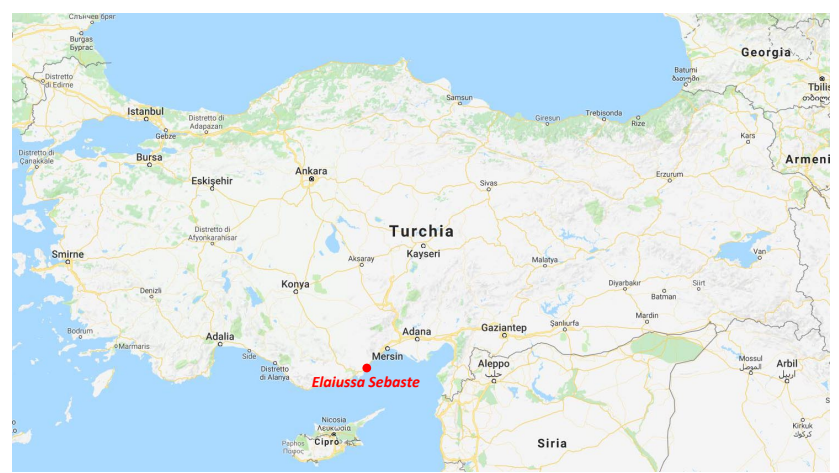

Figure 1. The position of the archaeological site of Elaiussa Sebaste.

University of Rome since 1995 under the guidance of Professor Eugenia Equini Schneider.

The excavations conducted in the last ten years have brought to light many buildings such as the temple in the southwestern area, the theatre, the agora-basilica, the thermal spas, the palace and the Necropolis in the northwest and two harbours (Figure 2).

In the years the survey of new excavation sites goes to enrich the already complex database of information both of the excavation areas that the finds (Equini Schneider, 2008b). At present, the archaeological area covers approximately $2 \mathrm{~km}^{2}$.

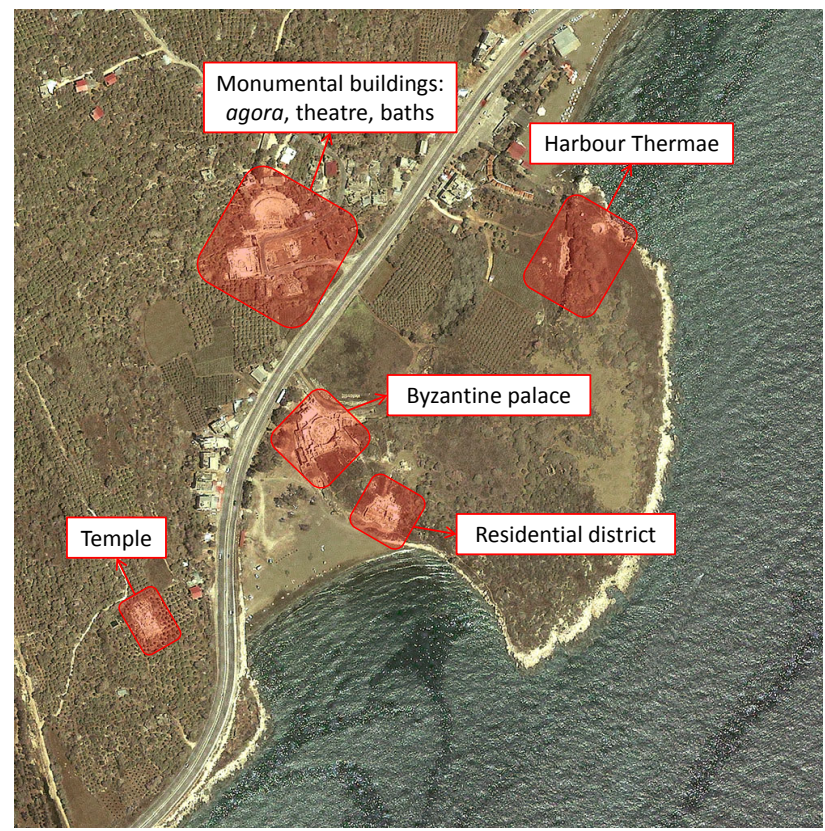

Figure 2. The main excavation areas of Elaiussa Sebaste.

\subsection{The residential district}

In 2005 the investigation of the archaeological site of Elaiussa Sebaste focused on an area located along the shores of the southern harbour of the city. This area, named residential district, is attested on the southernmost of several, irregular terraces at different height along the slopes of the rocky hill facing the harbour (Figure 3).

These terraces are connected by a system of stepped paths or inclined ramps, generally with non-linear paths. This morphological configuration is the first cause of the complexity of the area for the survey execution.



Figure 3. The residential district of Elaiussa Sebaste.

The original plant of the district can be ascribed to the Hellenistic age. The excavation activities revealed part of a residential area whose latest and best-preserved phase is to be ascribed to the Early Byzantine period.

Moreover, the lower terrace, located in the southern section of the area, had been arranged to host a workshop for the production of LR1 (Late Roman 1) amphora. This type of amphorae was enormously diffused in the Mediterranean area in the late ancient and proto-Byzantine age. The most outstanding archaeological remain in this area was a wellpreserved door, complete of frame and lintel, connected with a large portion of a wall built in small blocks.

The uniqueness of this site lies in the discovery of an entire production complex in a good state of conservation. Because kiln contexts with the relative functional annexes are little known and very rarely investigated extensively. Besides the kiln, other rooms meant for handcraft activities - storage of raw materials, a clay settling pool, water adduction pipes - were located in close vicinity; the location of the kiln and of the atelier, apparently, was due to the close connection with the harbour (Iacomi, 2013).

The industrial complex was accessible from the south, via a sloping ramp (about $3 \mathrm{~m}$ wide) that ran parallel to the great southern boundary wall of the complex. The ramp was in direct communication with the quays and with the possible landing facilities of the harbour.

This case is peculiar because the kiln was inserted in a unitary context that also includes structures for other purposes. The kiln was independent of the residential and commercial areas that occupied the overlying terraces, with their own independent accesses.

In the upper terraces, there were structures used as housing functions with attached craft and commercial activities. The individual building units, sometimes organized around uncovered courtyards, were often developed in height on two or more floors, as evidenced by the presence of stairs as well as by the collapsing layers of the different floor levels and roofing. The life of the district continued until the middle of the VII century, when the abandonment of the area began, which shared the same fate as most of the areas of Elaiussa Sebaste.

\section{DATA ACQUISITION}

The TLS survey was performed to produce a high-resolution 3D model of the residential district of the archaeologic site. This type of survey gives the present state of monuments. It involves 
a series of data acquisition for the determination of the shape, size and position of the object in 3D space (Amans et al, 2013). The residential district has a shape similar to a square of $40 \mathrm{~m}$ side with the structure distributed on three terraces.

To execute the TLS survey, we planned to divide the residential district ideally into three areas, in function of the different terrain height; each part had an overlap zone with the close one necessary for the step of scan registration. These three areas were called "Area A", "Area B" and "Area C". The "Area A" and "Area B" are related to residential part of the district, while "Area C".is related to the industrial part (Figure 4).

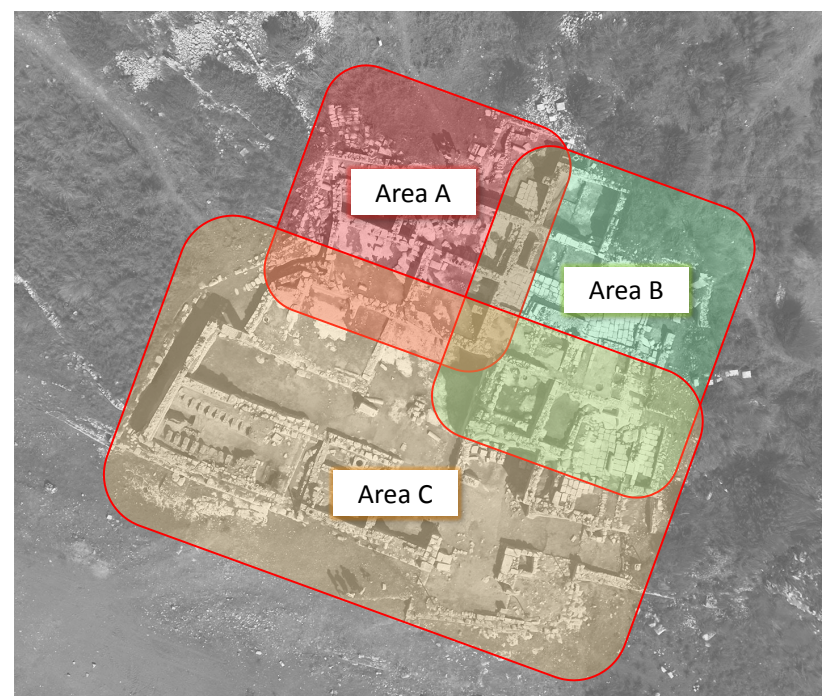

Figure 4. The three areas of scan acquisition.

Due to the complexity of the archaeological structures, we planned to execute one scan for each room. In the rooms where walls remains were too tall more than one scan was planned. A total of 57 scans were planned and carried out; figure 5 shows the scan positions.

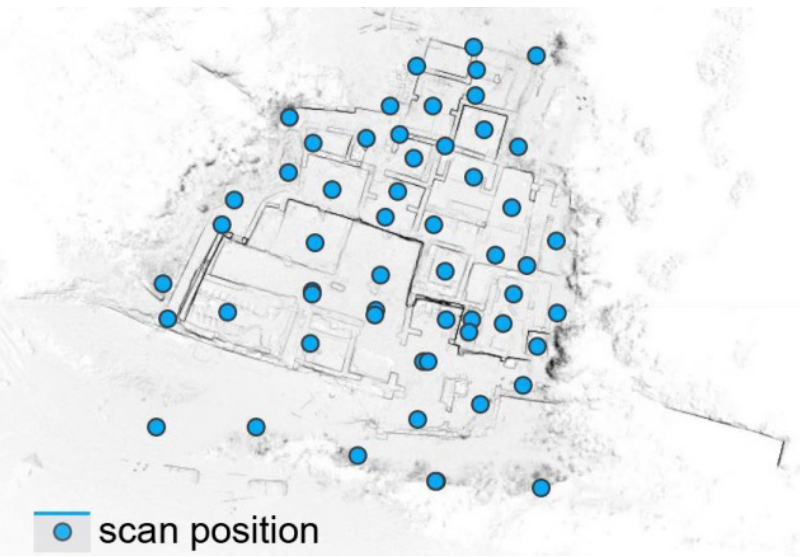

Figure 5. Scan positions.

To execute the survey was used the laser scanner Faro Focus 3D (Figure 6). The Faro Focus 3D is a high-speed laser scanner that uses phase shift technology to measure the distance. The point measurements reach up to 976,000 times per second; the distance range is of $0.6 \mathrm{~m}-120 \mathrm{~m}$ with low ambient light and normal incidence to a $90 \%$ reflective surface. The ranging error is of $\pm 2 \mathrm{~mm}$ at $10 \mathrm{~m}$ and $25 \mathrm{~m}$, each at $90 \%$ and $10 \%$ reflectivity. The use of such scanner has facilitated the survey operations thanks to its small size, long battery life and large field of view.

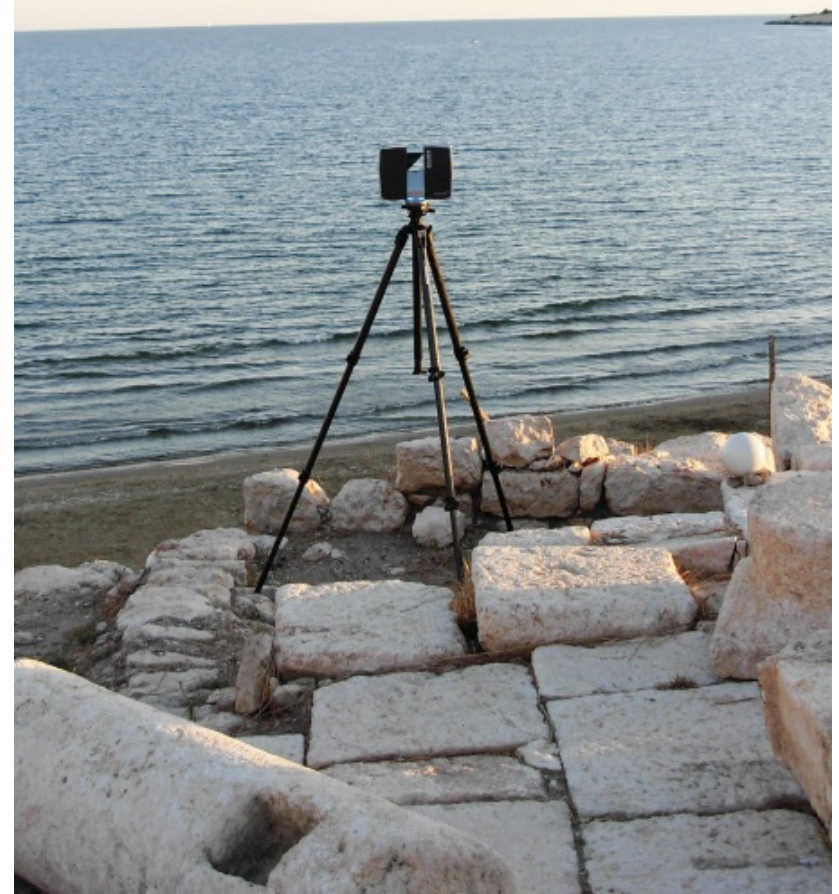

Figure 6. Faro Focus 3D.

The first trouble was the high ambient temperature of the site, very sunny because of its position, in front of the seaside. It has forced to reduce the duration of the working sessions, because the measures performed by the scanner, above the internal temperature of $52^{\circ} \mathrm{C}$, became unreliable.

The second difficulty was the planning of targets position necessary for the scans registration due to the high number of obstructions. The walls of many houses of the district exceeded $2 \mathrm{~m}$ of high and the terrain has a very complex morphology (Figure 7).

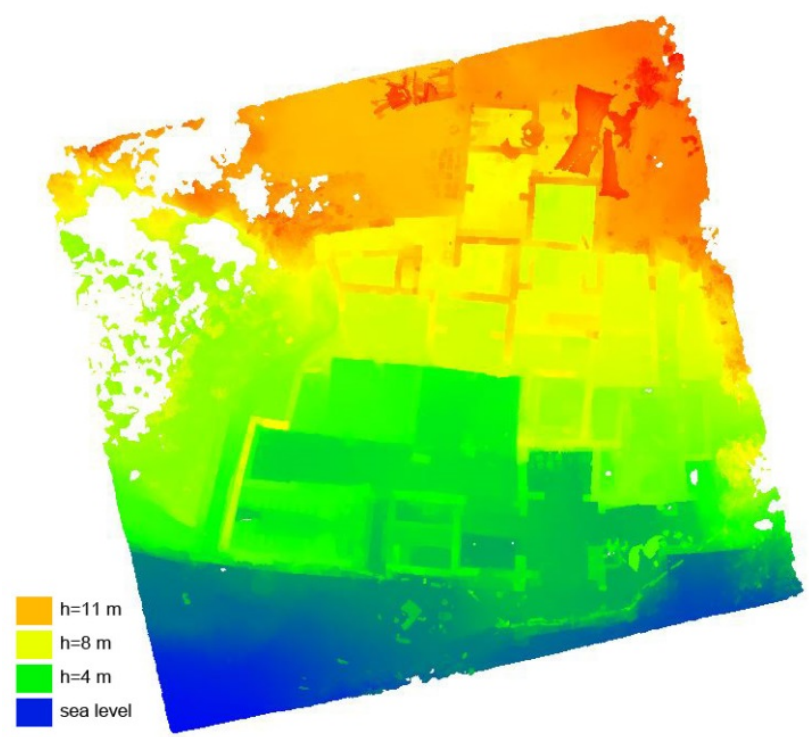

Figure 7. Height distribution of the site.

For the connection between scans were used two types of targets, spherical and planar. The spherical targets (Figure 8) were used for the connection between the various scans, on the 


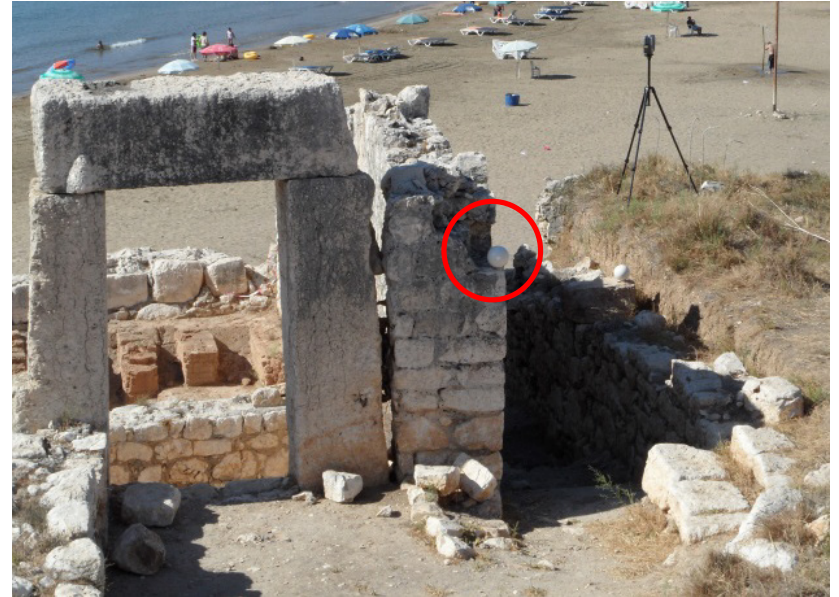

Figure 8. Spherical target.



Figure 9. Planar target.

other hand, the planar targets (Figure 9) were used only in the area with the better logistics condition.

In this area, corresponding to the kiln position was performed a topographic survey to georeferenced the $3 \mathrm{D}$ dataset in a cartographic system. The topographic survey was carried out by a static GNSS survey in three different points. These points were connected with the topographic network of the site. The points were used also for the topographic survey of the planar targets performed by total station.

\section{DATA PROCESSING}

The different scans produced a total point cloud of about 300 million points (Figure 10). This number of points has made data processing particularly difficult. So, for scan registration, raw data were divided into the 3 three areas and were processed according to the workflow in figure 11 .

Scene software package by Faro was used to scans data processing; it is capable of providing fully automatic recognition of the targets and of different natural constraints such as floors, edges and points for scans registration.

In the first step, every single scan has been subjected to a preprocessing to recover targets and delete outlier. Then, the targets were used for scans registration; the scans were registered according to the appertaining area. Scan registration was also optimized through a cloud-to-cloud process.

At the end, this first registration "Area C" was georeferenced using the planar target in the cartographic system. The georeferencing process was necessary to link the residential district with the other findings of this wide archaeological site.



Figure 10. Point cloud portion.

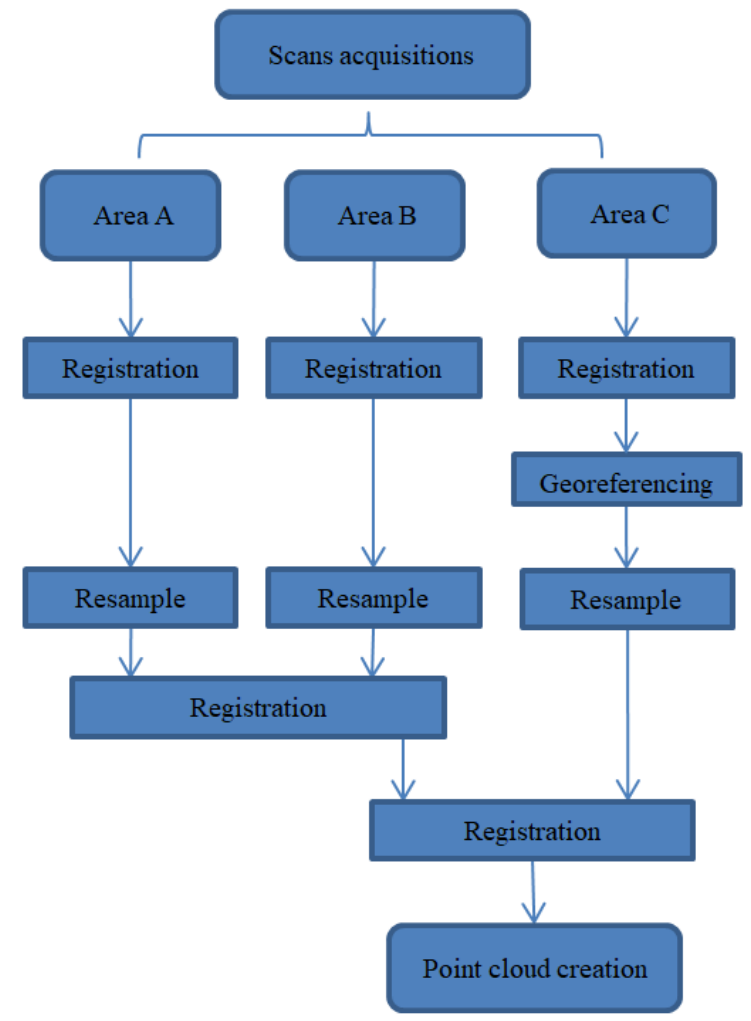

Figure 11. Workflow.

We did this operation before the following step, the resample, to preserve the accuracy of planar targets position.

The registered scans of each area afterwards have been resampled with a "uniform" filter selecting a resolution of 0.003 $\mathrm{m}$ (a value adequate to the survey purpose) and a priority of curvature equal to 8 on a scale from 1 to 10 . The operations of "filtering" represent the first step in the processing of laser scanning data and have the purpose of reducing the redundancy of the scans.

The last step of this workflow is the registration of "Area A" and "Area B" each other. The Root Mean Square (RMS) of this operation was of $\pm 0.002 \mathrm{~mm}$. These two areas were merged and were registered on georeferenced Area C; an RMS of $\pm 0.003 \mathrm{~m}$ was obtained in this step.

The areas were merged in a single model consists of about 168 million points. 


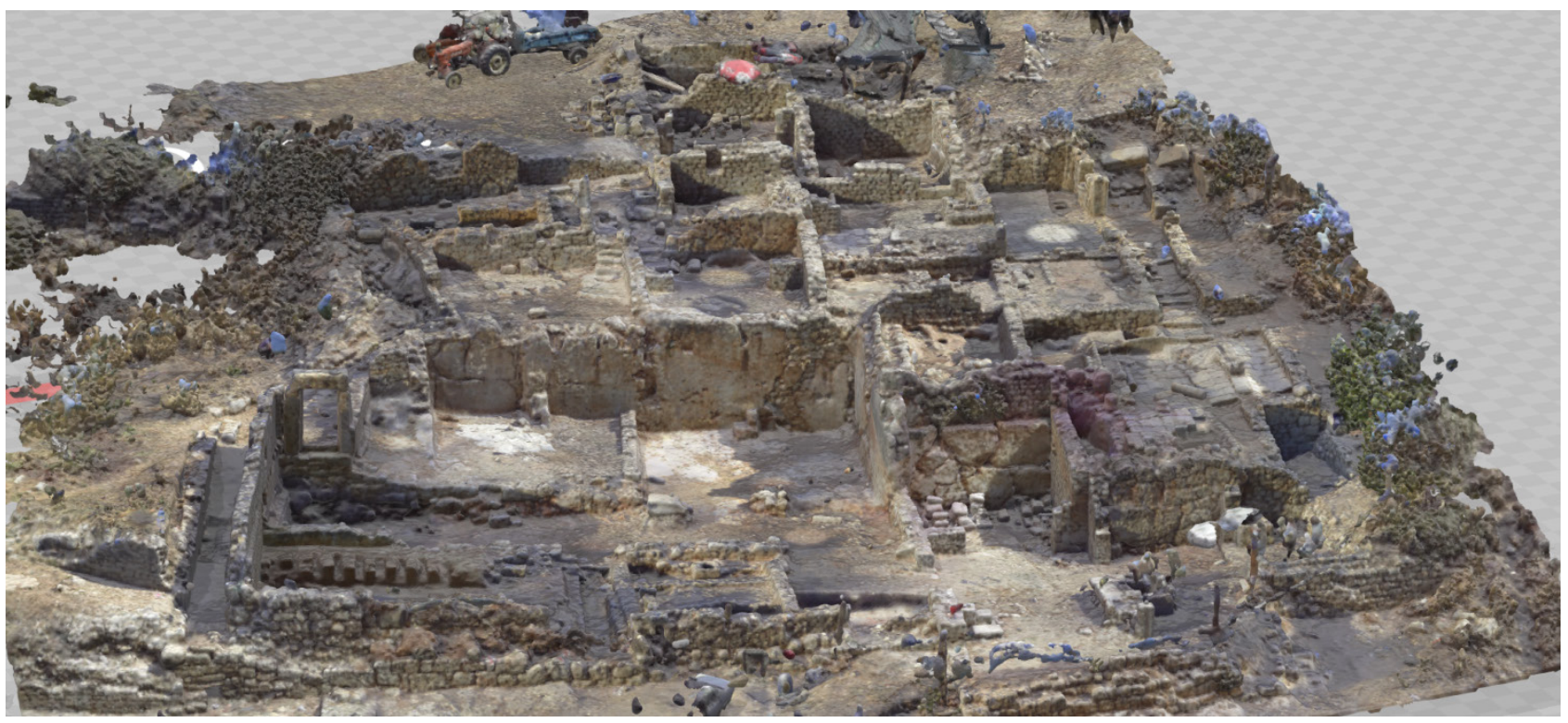

Figure 12. Polygonal model

The generation of the polygonal model, from these merged points, was done creating a mesh composed of about 50 million triangles (Figure 12).

\section{RESULTS}

The results obtained in the $3 \mathrm{D}$ documentation campaign Elaiussa Sebaste showed that the described workflow was efficient in both data acquisition and processing time. The main goal of this work was the creation of a 3D polygonal model. The generated model can provide a unified description of the complex settlement organization with a resolution of $0.003 \mathrm{~m}$ and a percentage of holes less of $3 \%$; from this model we extracted the two-dimensional plans, that were compared with the surveys made by archaeologists during the various excavation campaigns (Figure 13), and cross sections (Figures 14, 15 and 16) useful to archaeologists in the analysis of the complex morphology of the residential district.

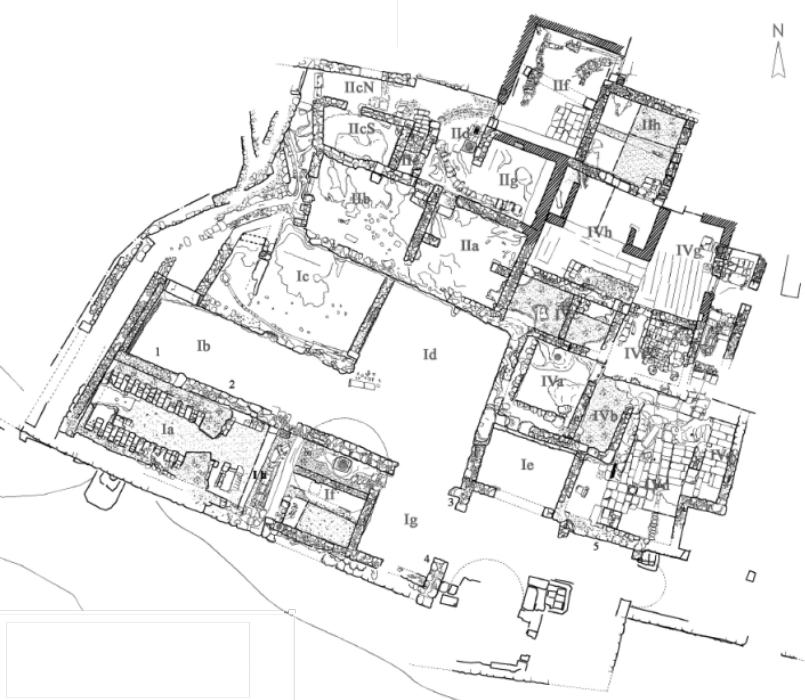

Figure 13. Two-dimensional plan of the district (from Iaocomi, 2013, drawing by B. Braini)

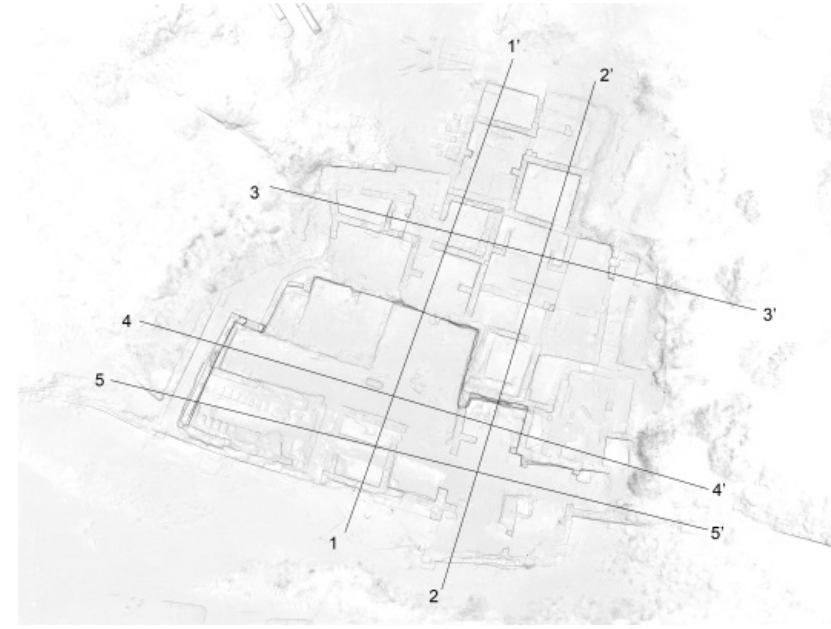

Figure 14. Planimetric schema of cross-section.

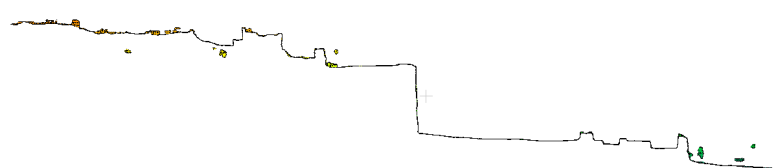

Section 1-1

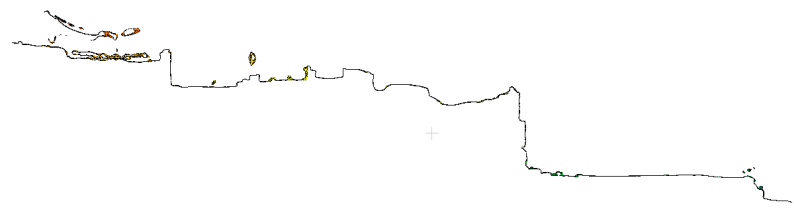

Section 2-2

Figure 15. Cross sections extracted from the 3D model (rough direction: north-east / south-west) 


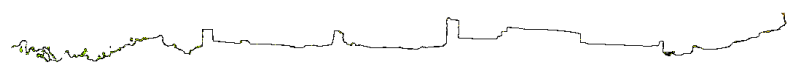

Section 3-3'



Section 4-4,

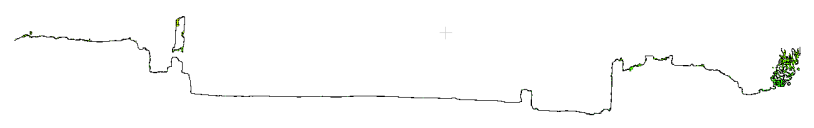

Section 5-5,

Figure 16. Cross sections extracted from the 3D model (rough direction: north-west / south-east)

\section{CONCLUSIONS}

This work describes a process of TLS survey and 3D modelling to create a digital reconstruction of a complex area of an archaeological site. The application of TLS has contributed to the knowledge and the understanding of the residential district of Elaiusse Sebaste in Turkey.

A specific procedure was developed to improve the method for data acquisition and processing.

This procedure has allowed solving field problems, registration and data management issues.

For archaeological site conservation and development, the metrically accurate dataset provided by the survey's spatial data acquisition has already proved invaluable in facilitating quantitative analysis and planning of work to be carried out at this site. Doubtless, it will be used for these purposes in the future, in concert with management plans for the site. Another important feature of the spatial database is its ability to visualize proposed interventions using a precise and realistic 3D model of the site.

\section{REFERENCES}

Amans, O. C., Beiping, W., Ziggah, Y. Y., Daniel, A. O., 2013, The need for 3D laser scanning documentation for select Nigeria cultural heritage sites European Scientific Journal vol.9, No.24.

Costantino, D., Angelini, M.G., Baiocchi, V., 2016. Integrated surveying for the archaeological documentation of a neolithic site. Geographia Technica, 11 (2), pp. 39-49.

Equini Schneider, E., 2008a. Elaiussa Sebaste: a Port City between East and West , Homer Kitabevi, book.

Equini Schneider, E., 2008b. "Elaiussa Sebaste: Six Centuries of History", "International Conference on Rough Cilicia : New Archaeological and Historical Approaches".
Galeazzi, F., 2016. Towards the definition of best 3D practices in archaeology: Assessing 3D documentation techniques for intra-site data recording. Journal of Cultural Heritage, 17, pp. 159-169.

Gonzalez-Aguilera, D, Campo-Sanchez, A, Hernandez-Lopez, D, Pozo, S, 2017. Optimized Planning of Terrestrial Laserscanner Surveys in Complex Archaeological Environments. International Journal of Earth \& Environmental Sciences, 2: 143, pp. 1-8.

Grussenmeyer, P., Alby, E., Landes, T., Koehl, M., Guillemin, S., Hullo, J. F., Assali, P., and Smigiel, E., 2012. Recording approach of heritage sites based on merging point clouds from high resolution photogrammetry and terrestrial laser scanning, Int. Arch. Photogramm. Remote Sens. Spatial Inf. Sci., XXXIXB5, pp. 553-558, doi:10.5194/isprsarchives-XXXIX-B5-5532012.

Hatzopoulos, J.N., Stefanakis, D., Georgopoulos, A., Tapeinaki, S., Volonakis, P., Liritzis, I., 2017. Use of various surveying technologies to 3D digital mapping and modelling of Cultural Heritage structures for maintenance and restoration purpose: the Tholos in Delphi, Greece. Mediterranean Archaeology and Archaeometry, Vol. 17 No 3, pp. 311-336.

Iaocomi, V., 2013, Private architecture and building techniques at Alaiussa Sebaste, Isauria (Rough Cilicia) in late antiquity and early Byzantine period. A methodological approach. In $K$. Levent Zoroğlu'na Armağan Studies in Honour of K. Levent Zoroğlu.

Lerma, J. L., Navarro, S., Cabrelles, M., Villaverde, V., 2010. Terrestrial laser scanning and close range photogrammetry for 3D archaeological documentation: the Upper Paleolithic Cave of Parpalló as a case study. Journal of Archaeological Science, 37, pp. 499-507.

Lo Brutto, M., Sciortino, R., Garraffa, A., 2017. RPAS and TLS tecniques for archaeological survey: the case study of the archaeological site of Eraclea Minoa (ITALY). Int. Arch. Photogramm. Remote Sens. Spatial Inf. Sci., XLII-2/W3, pp. 433-438, doi:10.5194/isprs-archives-XLII-2-W3-433-2017.

Remondino, F., Campana, S., 2014. 3D Recording and Modelling in Archaeology and Cultural Heritage - Theory and Best Practices, BAR International Series 2598, Oxford, 2014.

Torres-Martínez, J. A., Seddaiu, M., Rodríguez-Gonzálvez, P., Hernández-López, D., González-Aguilera, D., 2016. A MultiData Source and Multi-Sensor Approach for the 3D Reconstruction and Web Visualization of a Complex Archaelogical Site: The Case Study of "Tolmo De Minateda". Remote Sensing, 8, 550, pp. 1-25. 